AperTO - Archivio Istituzionale Open Access dell'Università di Torino

\title{
Biofuels Production from Renewable Resources
}

\section{This is a pre print version of the following article:}

Original Citation:

\section{Availability:}

This version is available http://hdl.handle.net/2318/1807924

since 2021-09-30T21:42:20Z

Published version:

DOI:10.1002/bab.2046

Terms of use:

Open Access

Anyone can freely access the full text of works made available as "Open Access". Works made available under a Creative Commons license can be used according to the terms and conditions of said license. Use of all other works requires consent of the right holder (author or publisher) if not exempted from copyright protection by the applicable law. 


\section{Editorial to the BAB Special Issue: "Biofuels Production from Renewable Resources"}

\section{Guest Editors:}

Jie Bao (jbao@ecust.edu.cn) East China University of Science and Technology Gianluca Catucci (gianluca.catucci@unito.it) Università degli Studi di Torino, Italy

Francesca Valetti (francesca.valetti@unito.it) Università degli Studi di Torino, Italy

Biofuels are emerging as the most important alternative to petroleum-derived transportation fuelsand biomasses are the primary source of renewable energy for the production of chemicals and fuels. The term biomass refers to organic matter deriving from various feedstock such as wood and other lignocellulosecontaining low-value biomasses, agricultural crops and other green wastes, animal wastes, aquatic plants and wastes. Biofuels can be solid, liquid or gas fuels. A variety of processes that exploit the transformation of a suitable biomass into a higher added value product are now available. The main advantages of producing and using biofuels are that these raw materials are generally available in many different areas of the world and that they generate low net greenhouse gas emissions, therefore minimizing the environmental impact.

In this special issue we will focus on four key determining aspects of biofuels production from renewable resources. 1) Innovative processes for the production of bioethanol, butanol and methane; 2) New enzymatic technologies for the modification of lignocellulose matrices; 3) The role of positive and negative modulators on biofuel production; and 4) the recovery of other value-added products from biofuel-producing wastes. 


\section{1) Innovative processes for the production of bioethanol, butanol and methane.}

Oil palm empty fruit bunch (OPEFB) is a biomass obtained in palm oil mills that can be an important resource of fuels and chemicals. Zhai et al. [1] demonstrate the feasibility of an innovative integrative process that includes dilute alkaline pretreatment, cellulolytic enzyme production, OPEFB hydrolysis and co-fermentation with a hybrid xylose-fermenting yeast. Their work opens new perspectives for the use of OPEFB biomass to produce ethanol. On the same matrix (palm empty fruit bunches or EFB), Campioni et al. [2] propose an integrated biorefinery process. This approach exploits a sequence of steps involving chemical pretreatment, enzymatic saccharification and glucose fermentation in a separate hydrolysis and fermentation. The hydrolysate was employed in bioethanol production by a new isolate Candida pelliculosa CCT 7734.

Narayanasamy et al. [3] report acetone-butanol-ethanol (ABE) fermentation of sugarcane bagasse (SCB) hydrolysate using Clostridium beijerinckii strains. The authors developed a cost-effective SCB medium that does not require enzymatic hydrolysis, supplementation of extra carbon sources or expensive nitrogen sources. The data demonstrate a high potential for the developed costeffective medium in biofuel production. The medium could also be potentially used for production of other value-added chemicals.

Hong et al. [4] propose a methodology for the production of biobutanol from red algal biomass. Using a diluted sulfuric acid and a newly isolated Clostridium sp. strain $W K$ they present a new and efficient way to produce biobutanol from marine biomass feedstock, exploiting the potential of the so called "blue" bioeconomy.

Methanogens are responsible for the last step in anaerobic digestion in which methane, a gas biofuel, is produced. Since methanogens are known to be cometabolizers of chlorinated pollutants, Paulo et al. [5] focused their work on the effect of nickel, cobalt and iron on the growth of M. barkeri. The data show 
how metal addition improves 1,2-dichloroethene dechlorination to vinyl chloride, indicating that metal ions can be a limiting factor in methanogenesis and dechlorination.

\section{2) New enzymatic technologies for the modification of lignocellulose matrices.}

Increasing demand of biomass-derived biofuels could cause a shift of production of food crops to biofuels crops, thus posing serious ethical questions. Indeed, lignocellulosic material could become an attractive substrate for biofuels production because of its extensive production and low cost, making it the most abundant and least used resource of fuels and raw materials. Increased efficiency of lignin exploitation is linked to improved enzyme-based degradation.

In their review, Catucci et al. [6] underline the importance of lignocellulose as a biomass source in the general context of an increased energy demand. They stress the potential use of a specific class of enzyme, dye-decolorizing peroxidases (DyP) in lignin degradation. The review envisions the improvement of the activity of DyPs against lignin to reach satisfactory conversion levels for industrial applications. In line with the requirements for sustainable scale-up, Akpinar and Urek [7] used cherry waste (CW) collected from industry as substrate and Pleurotus eryngii as the microorganism to increase production of lignocellulolytic enzymes such as laccase (Lac), manganese peroxidase $(\mathrm{MnP})$, lignin peroxidase $(\mathrm{LiP})$, carboxymethyl cellulase (CmCase), xylanase, exoglucanase, $\beta$-glucosidase (BGLA). The data show that $P$. eryngii adapted to all solid-state fermentation conditions and resulted in increased enzymatic activities that also demonstrated decolorizing performance. Dillies et al. [8] reported on three laccase mediator systems (LMS) to depolymerize the major industrial lignins (organosolv lignin, Kraft lignin, and sodium lignosulfonate). Their data show that enzymatic depolymerization of these lignins can be achieved by LMS using laccase from 
Trametes versicolor, a mediator and a cosolvent to enhance the solubilization of lignins.

\section{3) The role of positive or negative modulators on biofuel production}

Several different chemical or physical agents can act as positive or negative modulators of biofuels production. They can exert a role on the growth of the microorganism or directly on the activity of a specific enzyme.

Cheng et al. [9] present the effects of different concentrations of a negative modulator, the simulated flue gas, onto algal growth. Photosynthetic activities were evaluated for both Chlorella sp. AE10 and Chlorella sp. $C v$. The data indicate that Chlorella sp. $C v$ can tolerate full simulated flue and could be used for $\mathrm{CO}_{2}$ fixation from the simulated flue gas.

In their paper, Wang et al. [10] investigate the effect of negative modulators such as formic acid, coumaric acid, and furfural on acetone-butanol-ethanol (ABE) production from corn stover hydrolysate by Clostridium acetobutylicum CICC 8016. Correlation analysis revealed that formic acid, coumaric acid and total phenols were the major compounds inhibiting ABE production. The data show how a successful mitigation strategy for removal of the inhibitors can be achieved via absorption with resin D301, leading to enhanced ABE production.

Crop residue and animal manure at different value chain levels are only partially made a commodity for biofuel production with significant negative impacts on the global sustainability of the agriculture sector. Bello et al. [11] tested Biochar addition, within cattle manure composting process, as a positive modulator in the nitrogen transformation process. The results indicate that Biochar addition accelerated organic matter degradation and improved nitrogen mineralization.

\section{4) The recovery of other value products from biofuels-producing waste}


D-Psicose is a value-added product that can often be obtained from biomass sources that are employed for biofuels production. D-Psicose 3-epimerase is an enzyme that catalyzes the synthesis of D-psicose from D-fructose. In their study, Fu et al. [12] cloned the D-psicose 3-epimerase (RDPE) from Ruminococcus sp. and expressed it in Bacillus subtilis A311. RDPE expression was increased using a two-step $\mathrm{pH}$ regulation of segmented fermentation. This system provides an important experimental basis for the industrial-scale production of RDPE.

As Guest Editors, we would like to thank all the authors for their contribution in this issue. We believe that their articles represent highly innovative recent discoveries and technology developments in biofuels production from renewable resources. We hope that their work can be helpful for both experts and newcomers of the field.

Finally, we would also like to express our gratitude to the Editors-in-Chief, Prof. Gianfranco Gilardi and Prof. Jian-Jiang Zhong, as well as the Managing Editor Gwen Taylor and the rest of the editorial team for their efforts in making this special issue possible.

\section{References}

1. Zhai, L., Manglekar, R.R., Geng, A. (2019) Enzyme production and oil palm empty fruit bunch bioconversion to ethanol using a hybrid yeast strain. Biotechnology and Applied Biochemistry, bab.1816.

2. Campioni, T.S., Soccol, C.R., Libardi Junior, N., Rodrigues, C., Woiciechowski, A.L., Letti, L.A.J., Vandenberghe, L.P. de S. (2019) Sequential chemical and enzymatic pretreatment of palm empty fruit bunches for Candida pelliculosa bioethanol production. Biotechnology and Applied Biochemistry, bab.1826.

3. Narayanasamy, S., Chan, K.L., Cai, H., Abdul Razak, A.H.B., Tay, B.K., Miao, H. (2020) Biobutanol production from sugarcane bagasse by 
Clostridium beijerinckii strains. Biotechnology and Applied Biochemistry, bab. 1865.

4. Hong, Y., Chen, C., Wu, Y. (2019) Biobutanol production from sulfuric acid-pretreated red algal biomass by a newly isolated Clostridium sp. strain WK. Biotechnology and Applied Biochemistry, bab.1820.

5. Paulo, L.M., Hidayat, M.R., Moretti, G., Stams, A.J.M., Sousa, D.Z. (2020) Effect of nickel, cobalt, and iron on methanogenesis from methanol and cometabolic conversion of 1,2-dichloroethene by Methanosarcina barkeri. Biotechnology and Applied Biochemistry, bab.1925.

6. Catucci, G., Valetti, F., Sadeghi, S.J., Gilardi, G. (2020) Biochemical features of dye-decolorizing peroxidases: current impact on lignin degradation. Biotechnology and Applied Biochemistry, bab.2015.

7. Akpinar, M., Ozturk Urek, R. (2020) Decolorization and degradation potential of enhanced lignocellulolytic enzymes production by Pleurotus eryngii using cherry waste from industry. Biotechnology and Applied Biochemistry, bab.1846.

8. Dillies, J., Vivien, C., Chevalier, M., Rulence, A., Châtaigné, G., Flahaut, C., Senez, V., Froidevaux, R. (2020) Enzymatic depolymerization of industrial lignins by laccase-mediator systems in 1,4-dioxane/water. Biotechnology and Applied Biochemistry, bab.1887.

9. Cheng, D., Li, X., Yuan, Y., Zhao, Q. (2019) Kinetic model for effects of simulated flue gas onto growth profiles of Chlorella sp. AE10 and Chlorella sp. Cv. Biotechnology and Applied Biochemistry, bab.1829.

10. Wang, F., Dong, Y., Cheng, X., Xie, H., Song, A., Zhang, Z. (2020) Effect of detoxification methods on ABE production from corn stover hydrolysate by Clostridium acetobutylicum CICC 8016. Biotechnology and Applied Biochemistry, bab.1881.

11. Bello, A., Deng, L., Sheng, S., Jiang, X., Yang, W., Meng, Q., Wu, X., Han, Y., Zhu, H., Xu, X. (2020) Biochar reduces nutrient loss and improves microbial biomass of composted cattle manure and maize straw. Biotechnology and Applied Biochemistry, bab.1862.

12. Fu, G., Zhang, S., Dong, H., Chen, J., Tu, R., Zhang, D. (2019) Enhanced production of D -psicose 3-epimerase in Bacillus subtilis by regulation of segmented fermentation. Biotechnology and Applied Biochemistry, bab.1831. 